\title{
Enterprise Financial Management Problems and Countermeasures
}

\author{
Chao Wang
}

\author{
Shaanxi Academy of Governance, Xi'an 710068, China
}

Keywords: Financial management, Information distortion, Internal control.

\begin{abstract}
With the increasing development and improvement of modern enterprise system, enterprise financial management problems are increasing day by day. How enterprises face these problems in development is the difficulty placed in front of entrepreneurs and related employees. By analyzing the development trend of modern enterprise system, the author explores current problems enterprise financial management needs to solve, and puts forward measures and methods to solve such problems, such as the establishment of internal supervision and control system and so on.
\end{abstract}

\section{Introduction}

In daily business and production activities of enterprises, financial management should play a role in economic operation management. Nowadays, with the reform and opening up, socialist market economy is the inevitable wave. Enterprise financial management can not only promote the smooth operation of enterprises, but also ensure enterprises to remain stable in the fierce market competition, and as the backbone, contribute to the healthy and stable development of socialist market economy. It can be seen that strengthening enterprise financial management increasingly becomes the consensus problem in the society.

\section{Problems in Enterprise Financial Management to be Resolved}

With the deepening of reform and opening up in seventies and entering of socialist market economy in eighties, China's economy began to come to marketization and internationalization, and Chinese enterprises developed and grew rapidly. However, many problems followed and in enterprise economic operation, financial management still has many problems. With implementation of socialist market economy, market economy has become an invisible "hand", followed by the emergence of lack of credibility, and this is reflected in financial management. If enterprises pay less attention on management, financial operations may breed corruption. If corruption is not promptly resolved, normal business operation would suffer from a great risk. Therefore, to avoid this risk, it requires enterprises to value financial management in production and management, identify the existing financial management issues and promptly solve these problems, to provide a solid guarantee for the healthy and stable development of enterprises.

\section{Enterprise financial information distortion.}

As an important reference for the final business decisions, enterprise financial management problems must always get alerted. Pragmatic financial management system is an important guarantee for the healthy development of enterprises. Major enterprise decisions must refer the recent finance-related data, such as capital working situation, market demand orientation and other factors, to develop ultimate direction of development. If there is any financial management problem at this time, the major decision is built on the basis of wrong information, and then the consequences could be disastrous. The result may be as minor as that enterprises face some problems in the short-term production and operation, and enterprise development gets troubled, or as serious as that enterprises lose credibility and employees and relevant partners lose confidence in work, and finally enterprise normal production operation suffers from a crisis of credibility, and in severe cases enterprises are on the verge of insolvency. Thus, at any time, enterprises should pay attention to financial management.

Modern Enterprises often have financial distortion problem, presented as follows. First, business income and expenses have distortion problem. In financial operation, some financial staff has ulterior 
motives for seeking their own interests, and they make untrue accounting illegally, thus resulting in information distortion of income and expenditures. Second, financial statements present distortion during recording. Some enterprises, in order to evade tax, cover normal business conditions and corporate profits, to create false financial statements. Usually there are two sets of such financial statements, one for internal circulation and the other for external publicity. Third, there is distortion in accounts keeping. In enterprise operation, financial management sector lacks rigorous and pragmatic attitude during setting and recording accounts, easily leading to financial management loopholes.

\section{Unsound enterprise internal control system.}

How to well resolve enterprise internal control problems is the difficulty placed in front of business operators. To strengthen financial management, enterprises must establish a complete set of practical internal control systems within enterprises, and conduct full-range financial control through starting from the internal, which can help financial department operate more equitably and efficiently, improve the quality of financial information, and ensure the authenticity and validity of enterprise financial information, so as to promote the healthy and stable business operation and development. However, in enterprise operation and management, internal control has limitations in some aspects. For example, even strong internal control is carried out, but the inevitable question is that most related personnel of the internal control system are still from financial department. If daily work of these two jobs is closely linked, check on financial work is likely to remain on the surface. Especially, in operation of some small and medium enterprises, financial management system often cannot reflect enterprise business situation for this time, and therefore frequent approval and publicity processes are likely to cause a crisis of confidence of employees. When enterprises determine to carry out certain important projects, if there is no sound financial internal control system and they cannot effectively track financial operation, then such projects will face great risk. Yet another problem is that there are still many problems in billing and reimbursement process of financial management. These defects will give an opportunity to persons who have selfish motives, there will be loss of direction in the event of investigating responsibility, and enterprises will suffer from great loss unable to be investigated. Therefore, when perfecting enterprise internal control direction, enterprises should focus on two aspects, internal organization, and form change, and innovate in these two aspects, in order to truly improve enterprise internal control system.

\section{Insufficient emphasis leading to weak internal financial control environment.}

Due to different levels of knowledge of enterprise leadership, some leaders do not have enough awareness of the establishment of internal financial system and preparation of related matters lacks enough attention. When setting internal financial control related staff, they feel they do not get enough attention, and naturally their attitudes towards their work are not stringent enough. After a long time, this will easily lead to marginalization of the internal financial control system, and enterprise operation management will have problems at different levels. Especially for some SMEs, due to small-scale production and operation, they often do not pay attention to the internal financial supervision, and it is difficult to form a sound financial management system and related institutions, therefore leading to the inevitable emergence of unpredictable problems in operation process.

\section{Low quality of enterprise financial management personnel and deficient level of financial management.}

As increasingly fierce competition between enterprises and institutions, any industry wants to obtain long-term stable development. And excellent human resources play the decisive role. In enterprise internal control system, only high-quality and high-standard management personnel can ensure optimization and development of enterprise financial situation ${ }^{[1]}$.

\section{Objective and Significance of Strengthening Enterprise Financial Management}

In business management, strengthening financial management is an important guarantee to promote healthy and stable business operation. For how to accomplish financial management, on the one hand, enterprises must resolutely implement financial regulations and relevant rules, which is the basic norm of enterprise operation, and on the other hand, enterprises must comply with national 
relevant policies and norms. All daily business activities should reflect legitimacy, authenticity and validity of relevant financial regulations and rules, to ensure legitimate, effective and public enterprise production and business activities.

Strengthening enterprise financial management is an important guarantee for production and operation. For reasons for operational problems of most enterprises, falseness and loopholes account a large proportion. Accordingly, enterprise financial management system should be responsible for production and operation, all employees and smooth running of socialist market economy. This is important to create aN honest and trustworthy market environment, and build a high-quality market economy development system ${ }^{[2]}$.

\section{Measures for Strengthening Enterprise Financial Management}

\section{Sticking to principles and enterprise financial information quality.}

In order to ensure fairness and stringency of enterprise financial management, enterprises should stick to principles in operation management. This requires enterprise financial management department, in all financial work, resolutely implements national relevant financial laws and regulations, and strictly complies with relevant financial rules and regulations, especially for initial financial accounting and registration, adheres to the principle of impartiality and unity, and carries out control from the source. At the same time, in production and marketing process, enterprises also should pay attention to the timeliness and comprehensiveness of information collection in financial management, and during accounting bookkeeping and accounting audit, perfect basic functions of accounting statistics, to ensure the quality of financial information. On the other hand, in financial management, enterprises should develop rigorous and scientific examination and approval of accounting statements, to ensure legitimate and pragmatic financial statements, correctly reflecting recent production and operation situation of enterprises, to facilitate to safely and efficiently perform related business decisions.

\section{Establishing a sound enterprise internal control system.}

In the foregoing, the author has pointed out the issues related to enterprise internal control system in China. With the development of the times, the importance of strengthening internal control becomes increasingly prominent. On the one hand it can help enterprises perform better business decisions, and on the other hand problems in accounting statistical need regulation and improvement from enterprise internal control system, thereby improving the quality of accounting and auditing, and promoting healthy and stable economic development. And for how to establish a sound internal control system, the author proposes to proceed from the following aspects.

First, improve the quality of internal control system related personnel, and hire high-level or professional students in colleges and universities, or working professionals to engage in related occupations, in order to ensure enterprise internal control system can better regulate and facilitate financial management, and can better improve scientificity and efficiency of internal control.

Second, improve enforcement of internal control system. Faced with defects and vulnerabilities of financial management, enterprises should immediately identify quickly and take relevant measures. If problems are caused by selfishness of financial practitioners, enterprises should take appropriate management and penalties. Only high-standard, strictly-required internal control system, and strict work-style, can realize the good function of internal control system in promoting enterprise operation.

Third, increase scientific and technological innovation, and actively introduce advanced production technology. In the twenty-first century, with the advent of knowledge economy, science and technology has become the first productivity, and application of science and technology in enterprise internal management system is increasingly widespread. To improve the technological level is the healthy and effective method to improve internal control. 


\section{Enhancing emphasis on financial management, and purifying internal financial management environment.}

From the development trend of Chinese enterprises for many years, it can be seen that, regardless of enterprise size, how advanced enterprise business is, and how good enterprise projects are, if problems arise in financial management, enterprise development will be accompanied by a lot of problems. This shows the important role of financial management in enterprise economic operation. Good financial management can help enterprises for better development; otherwise it will lead to various problems in enterprise economic operation. The staff engaged in enterprise financial management, should preserve their moral integrity, pay attention to their work, keep strict, pragmatic and meticulous work attitude, and in the event of uncontrollable financial situation, timely report to higher authorities.

Optimizing financial management personnel training, and improving their professional skills.

Enterprise financial management, as the high-level specialized work, has relatively higher requirements on quality of related personnel. Financial workers need to collate and analyze annual financial statements of business conditions, and a large number of finance-related data, and identify problems in enterprise business operation in order to provide correct decision advice and development direction for leaders.

\section{Strengthening supervision of financial management work.}

In enterprise financial management system, financial supervision is an indispensable element. In improvement of financial management, strengthening financial supervision, in particular on daily balance of payments, will be able to improve the financial quality of enterprises, and contribute better and easier development. With the increasingly economic competition in socialist market economy, to come out on top in a particular area, firmly stand in the fierce market competition, and occupy the dominant position, in addition to carrying out reform and innovation of financial management system, enterprises also need to establish and improve supervision system. Only in this way, can enterprises better improve the utilization efficiency of resources, prevent internal corruption, and promote the steady development of enterprise economy.

\section{Optimizing financial management tools and promoting management information construction.}

Enterprise financial management system relates to production and operation process. Therefore, in production and operation process, to effectively reflect the development of enterprises, optimization of financial management tools becomes indispensable. With the rise of knowledge economy in the twenty-first century, and growing level of information, means and methods of financial management should also make certain adjustments. Information management plays an increasingly important role in financial management. Promoting the use of science and technology in financial management, can improve efficiency of financial management, enhance accuracy of data analysis, and also save labor costs, to provide fast, effective and scientific data for enterprises as reference $^{[3]}$.

\section{Conclusions}

To sum up, financial management, as one of core competitiveness of enterprises, has increasingly become a strategic element many businesses emphasize. To stand out and occupy the dominant position in the fierce market competition, it is necessary for enterprises to improve financial management, establish a sound internal control system, increase the quality of relevant employees, and lift the professional level, in order to promote enterprise to move forward more robustly in the era of innovation. 


\section{References}

[1] Zhang Xuefen, Problems and Countermeasures of Enterprise Financial Management, Chinese Foreign Investment, 2013, 14: 62-63.

[2] Wen Fengbo, Pei Gengsheng, Gao Lei. Problems and Countermeasures of SME Financial Management, Journal of Hebei University (Philosophy and Social Science Edition), 2010, 04: 69-72.

[3] Liu Yi. Problems and Countermeasures of SME Financial Management, Economic Research Guide, 2015, 09: 145-147. 